\title{
MAKING TISSUE ENGINEERING SCAFFOLDS WORK. REVIEW ON THE APPLICATION OF SOLID FREEFORM FABRICATION TECHNOLOGY TO THE PRODUCTION OF TISSUE ENGINEERING SCAFFOLDS
}

\author{
E. Sachlos and J.T. Czernuszka* \\ Department of Materials, University of Oxford, Parks Road, Oxford, OX1 3PH, UK
}

\begin{abstract}
Tissue engineering is a new and exciting technique which has the potential to create tissues and organs de novo. It involves the in vitro seeding and attachment of human cells onto a scaffold. These cells then proliferate, migrate and differentiate into the specific tissue while secreting the extracellular matrix components required to create the tissue. It is evident, therefore, that the choice of scaffold is crucial to enable the cells to behave in the required manner to produce tissues and organs of the desired shape and size. Current scaffolds, made by conventional scaffold fabrication techniques, are generally foams of synthetic polymers. The cells do not necessarily recognise such surfaces, and most importantly cells cannot migrate more than $500 \mu \mathrm{m}$ from the surface. The lack of oxygen and nutrient supply governs this depth. Solid freeform fabrication (SFF) uses layer-manufacturing strategies to create physical objects directly from computer-generated models. It can improve current scaffold design by controlling scaffold parameters such as pore size, porosity and pore distribution, as well as incorporating an artificial vascular system, thereby increasing the mass transport of oxygen and nutrients into the interior of the scaffold and supporting cellular growth in that region. Several SFF systems have produced tissue-engineering scaffolds with this concept in mind, which will be the main focus of this review. We are developing scaffolds from collagen and with an internal vascular architecture using SFF. Collagen has major advantages as it provides a favourable surface for cellular attachment. The vascular system allows for the supply of nutrients and oxygen throughout the scaffold. The future of tissue engineering scaffolds is intertwined with SFF technologies.
\end{abstract}

Key Words: Tissue engineering, scaffold, collagen, synthetic polymers, solid freeform fabrication, rapid prototyping, artificial vascular system, microarchitecture.

*Address for correspondence:

J.T. Czernuszka

Department of Materials, University of Oxford,

Parks Road, Oxford, OX1 3PH, UK

FAX Number: +44-1865-273789

E-mail: jan.czernuszka@materials.ox.ac.uk

\section{Introduction}

This review will present the current state of the art of tissue engineering, with particular emphasis on the scaffolds on which tissue can be formed. The important role of the scaffold will be discussed and the conventional scaffold fabrication techniques will be introduced, highlighting the limitations of these fabrication techniques and the need to find other ways to create scaffolds with complex internal features. In particular, the use of solid freeform fabrication (SFF) to produce customised scaffolds with controlled internal microarchitecture will be addressed and the current SFF technologies being applied to scaffold fabrication will be reviewed.

\section{Tissue Engineering}

Tissue engineering is a multidisciplinary field which involves the 'application of the principles and methods of engineering and life sciences towards the fundamental understanding of structure-function relationships in normal and pathological mammalian tissues and the development of biological substitutes that restore, maintain or improve tissue function' (Shalak and Fox, 1988). The goal of tissue engineering is to surpass the limitations of conventional treatments based on organ transplantation and biomaterial implantation (Langer and Vacanti, 1993). It has the potential to produce a supply of immunologically tolerant 'artificial' organ and tissue substitutes that can grow with the patient. This should lead to a permanent solution to the damaged organ or tissue without the need for supplementary therapies, thus making it a cost-effective treatment in the long term (Patrick et al., 1998).

One of the principle methods behind tissue engineering involves growing the relevant cell(s) in vitro into the required three-dimensional (3D) organ or tissue. But cells lack the ability to grow in favoured 3D orientations and thus define the anatomical shape of the tissue. Instead, they randomly migrate to form a two-dimensional (2D) layer of cells. However, 3D tissues are required and this is achieved by seeding the cells onto porous matrices, known as scaffolds, to which the cells attach and colonise (Langer and Vacanti, 1993). The scaffold therefore is a very important component for tissue engineering.

Several requirements have been identified as crucial for the production of tissue engineering scaffolds (Hutmacher, 2001): (1) the scaffold should possess interconnecting pores of appropriate scale to favour tissue integration and vascularisation, (2) be made from material with controlled biodegradability or bioresorbability 
so that tissue will eventually replace the scaffold, (3) have appropriate surface chemistry to favour cellular attachment, differentiation and proliferation, (4) possess adequate mechanical properties to match the intended site of implantation and handling, (5) should not induce any adverse response and, (6) be easily fabricated into a variety of shapes and sizes. Bearing these requirements in mind, several materials have been adopted or synthesised and fabricated into scaffolds.

\section{Scaffold Materials}

Investigations into synthetic and natural inorganic ceramic materials (e.g. hydroxyapatite and tricalcium phosphate) as candidate scaffold material have been aimed mostly at bone tissue engineering (Burg et al., 2000). This is because these ceramics resemble the natural inorganic component of bone and have osteoconductive properties (LeGeros, 2002). However, these ceramics are inherently brittle and cannot match the mechanical properties of bone. It should be mentioned that bone is a composite comprising a polymer matrix reinforced with ceramic particles. The polymer is the protein collagen, $30 \%$ dry weight, and hydroxyapatite (HA), 70\% dry weight. Moreover, ceramic scaffolds cannot be expected to be appropriate for the growth of soft tissues (e.g. heart muscle tissue) considering that these tissues possess different cellular receptors and mechanical property requirements. Synthetic and natural polymers are an attractive alternative and versatile in their applications to the growth of most tissues.

\section{Synthetic polymers}

Aliphatic polyesters such as polyglycolic acid (PGA), polylactic acid (PLLA), their copolymers (e.g. PLGA) and polycaprolactone (PCL) are the most commonly used polymers for tissue engineering scaffold applications (Freed and Vunjak-Novakovic, 1998; Agrawal and Ray, 2001; Hutmacher 2001). The degradation products of these polymers (glycolic acid and lactic acid) are present in the human body and are removed by natural metabolic pathways. For a comprehensive review on synthetic polymers used in tissue engineering scaffolds, the reader is referred to Griffith (2000) and Hayashi (1994).

\section{Natural polymers}

Naturally derived protein or carbohydrate polymers have been used as scaffolds for the growth of several tissue types. By far the most popular natural polymer used for tissue engineering scaffolds is collagen. The reader is referred to Hayashi (1994) for a review on biodegradable natural polymers.

\section{Conventional Scaffold Fabrication Techniques}

Several techniques have been developed to process synthetic and natural scaffold materials into porous structures. These conventional scaffold fabrication techniques are defined herein as processes that create scaffolds having a continuous, uninterrupted pore structure which lacks any long-range channelling microarchitecture. A description of the different techniques follows.

\section{Solvent-casting particulate-leaching}

This technique involves producing a solution of PLLA in chloroform and adding salt particles of a specific diameter to produce a uniform suspension (Mikos et al., 1994, 1996). The solvent is allowed to evaporate leaving behind a polymer matrix with salt particles embedded throughout. The composite is then immersed in water where the salt leaches out to produce a porous structure. A lamination technique using chloroform as the binder was proposed to shape these scaffolds into 3D structures (Mikos et al., 1993a).

\section{Gas foaming}

A biodegradable polymer, such as PLGA is saturated with carbon dioxide $\left(\mathrm{CO}_{2}\right)$ at high pressures (Mooney et al., 1996). The solubility of the gas in the polymer is then decreased rapidly by bringing the $\mathrm{CO}_{2}$ pressure back to atmospheric level. This results in nucleation and growth of gas bubbles, or cells, with sizes ranging between 100$500 \mu \mathrm{m}$ in the polymer.

\section{Fibre meshes/fibre bonding}

Fibres, produced by textile technology, have been used to make non-woven scaffolds from PGA and PLLA (Cima et al., 1991). The lack of structural stability of these nonwoven scaffolds, often resulted in significant deformation due to contractile forces of the cells that have been seeded on the scaffold. This led to the development of a fibre bonding technique to increase the mechanical properties of the scaffolds (Mikos et al., 1993b). This is achieved by dissolving PLLA in methylene chloride and casting over the PGA mesh. The solvent is allowed to evaporate and the construct is then heated above the melting point of PGA. Once the PGA-PLLA construct has cooled, the PLLA is removed by dissolving in methylene chloride again. This treatment results in a mesh of PGA fibres joined at the cross-points.

\section{Phase separation}

A biodegradable synthetic polymer is dissolved in molten phenol or naphthalene and biologically active molecules such as alkaline phosphatase can be added to the solution (Lo et al., 1995). The temperature is then lowered to produce a liquid-liquid phase separation and quenched to form a two-phase solid. The solvent is removed by sublimation to give a porous scaffold with bioactive molecules incorporated in the structure.

\section{Melt moulding}

This process involves filling a Teflon mould with PLGA powder and gelatine microspheres, of specific diameter, and then heating the mould above the glass-transition temperature of PLGA while applying pressure to the mixture (Thompson et al.,1995a). This treatment causes the PLGA particles to bond together. Once the mould is removed, the gelatin component is leached out by immersing in water and the scaffold is then dried. Scaffolds produced this way assume the shape of the mould. The melt moulding process was modified to incorporate short fibres of HA. A uniform distribution of HA fibres through- 
out the PLGA scaffold could only be accomplished by using a solvent-casting technique to prepare a composite material of HA fibres, PLGA matrix and gelatine or salt porogen, which was then used in the melt moulding process (Thompson et al., 1995b).

\section{Emulsion freeze drying}

This process involves adding ultrapure water to a solution of methylene chloride with PGA (Whang et al., 1995). The two immiscible layers are then homogenised to form a water-in-oil emulsion, which is then quenched in liquid nitrogen and freeze-dried to produce the porous structure.

\section{Solution Casting}

PLGA is dissolved in chloroform and then precipitated by the addition of methanol (Reuber et al., 1987; Schmitz and Hollinger, 1988). Demineralised freeze-dried bone can be combined with the PLGA, and the composite material is then pressed into a mould and heated to $45-48^{\circ} \mathrm{C}$ for $24 \mathrm{~h}$ to create the scaffold.

\section{Freeze drying}

Synthetic polymers, such as PLGA, are dissolved in glacial acetic acid or benzene. The resultant solution is then frozen and freeze-dried to yield porous matrices (Hsu et al., 1997). Similarly, collagen scaffolds have been made by freezing a dispersion or solution of collagen and then freezedrying (Yannas et al., 1980). Freezing the dispersion or solution results in the formation of ice crystals that force and aggregate the collagen molecules into the interstitial spaces. The ice crystals are then removed by freeze-drying. The pore size can be controlled by the freezing rate and $\mathrm{pH}$; a fast freezing rate produces smaller pores (Dagalakis et al., 1980; Doillon et al., 1986). Unidirectional solidification has been used to create a homogenous 3D-pore structure (Schoof et al., 2000, 2001). Dehydration of the frozen collagen using ethanol and then critical point drying has also been used to make collagen scaffolds (Dagalakis et al., 1980, Sachlos et al., 2003). These collagen scaffolds are then crosslinked by either physical or chemical means to reduce the solubility, antigenicity and degradation rate. Physical crosslinking involves exposing to ultraviolet (Miyata et al., 1971) or gamma irradiation (Miyata et al., 1980), or dehydrothermal treatment (Weadock et al., 1983-84; Thompson and Czernuszka 1995). Chemical crosslinking is achieved by the use of bifunctional agents like glutaraldehyde (GTA) (Ruijgrok et al., 1994) and hexamethylene diisocyanate (Olde Damink et al., 1995) or by carboxyl group activation with carbodiimides (Weadock et al., 1983-84). Other natural polymers like chitin (Madihally and Matthew, 1999) and alginate (Glicklis et al., 2000) are also fabricated into scaffolds using freezing-drying.

\section{Limitations of current tissue engineering scaffolds}

Several detailed investigations have shown that cells attach to synthetic polymer scaffolds leading to the formation of tissue, summarised by Freed and Vunjak-Novakovic (1998). However, the degradation of synthetic polymers, both in vitro and in vivo conditions, releases acidic by-prod- ucts which raise concerns that the scaffold microenvironment may not be ideal for tissue growth. Lactic acid is releases from PLLA during degradation (Reed and Gilding, 1981), reducing the $\mathrm{pH}$, which further accelerates the degradation rate due to autocatalysis (Vert et al., 1994), resulting in a highly acidic environment adjacent to the polymer. Such an environment may adversely affect cellular function (Kohn et al., 2002). Cells attached to scaffolds are faced with several weeks of in vitro culturing before the tissue is suitable for implantation. During this period, even small $\mathrm{pH}$ changes (6.8-7.5) in the scaffold microenvironment can significantly affect bone marrow stromal cell expression of osteoblastic phenotypic markers (Kohn et al., 2002). Furthermore, particles released during polymer degradation can affect bone-remodelling processes (Wake et al., 1998) along with eliciting an inflammatory response and inducing bone resorption in vivo (Bergsma et al., 1995; Suganuma and Alexander, 1993). Moreover, current synthetic polymers do not possess a surface chemistry which is familiar to cells, that in vivo thrive on an extracellular matrix made mostly of collagen, elastin, glycoproteins, proteoglycans, laminin and fibronectin (Alberts et al., 1994). In contrast, collagen is the major protein constituent of the extracellular matrix and is recognised by cells (Kleinman et al., 1981) as well as being chemotactic (Postlethwaite et al., 1978). Collagen scaffolds presents a more native surface relative to synthetic polymer scaffolds for tissue engineering purposes. However, like other natural polymers, it may elicit an immune response (Arem, 1985). The antigenicity of collagen can be reduced by treating with pepsin to remove the telopeptide regions or by crosslinking (Chevally and Herbage, 2000).

Conventional scaffold fabrication techniques are incapable of precisely controlling pore size, pore geometry, spatial distribution of pores and construction of internal channels within the scaffold. Scaffolds produced by solvent-casting particulate-leaching cannot guarantee interconnection of pores because this is dependent on whether the adjacent salt particles are in contact. Furthermore, skin layers are formed during evaporation and agglomeration of salt particles makes controlling the pore size difficult (Hutmacher, 2001). Moreover, only thin scaffold cross-sections can be produced due to difficulty in removing salt particles deep in the matrix. For gas foaming, it has been reported that only $10-30 \%$ of the pores were interconnected (Mooney et al., 1996). Non-woven fibre meshes have poor mechanical integrity. Excluding gas foaming and melt moulding, conventional scaffold fabrication techniques use organic solvents, like chloroform and methylene chloride, to dissolve synthetic polymers at some stage in the process. The presence of residual organic solvent is the most significant problem facing these techniques due to the risks of toxicity and carcinogenicity it poses to cells.

In addition, conventional fabrication techniques produce scaffolds that are foam structures. Cells are then seeded and expected to grow into the scaffold. How- 


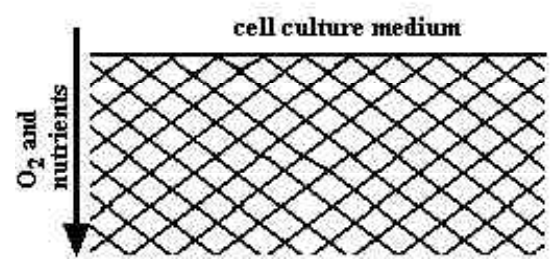

a) Tissue engineering scaffold which is an open-cell foam structure. Oxygen and nutrients are supplied from the liquid cell culture medium.

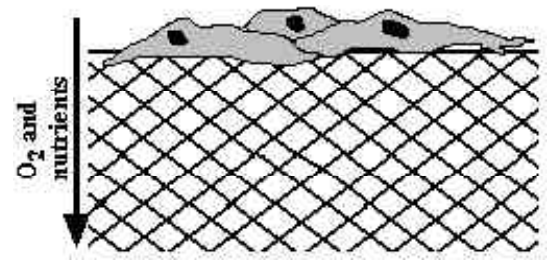

b) Cell seeding on scaffold.

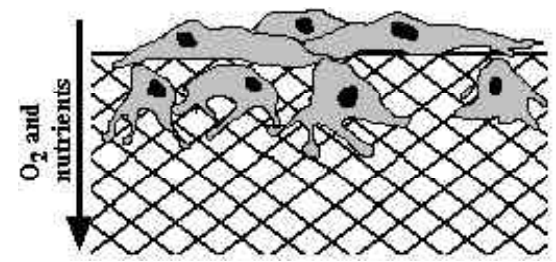

c) Cells start to proliferate and migrate into the pores of the scaffold.

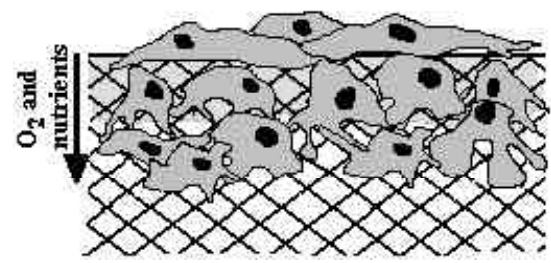

d) The cells fully colonise the pores and start to lay down their own extracellular matrix.

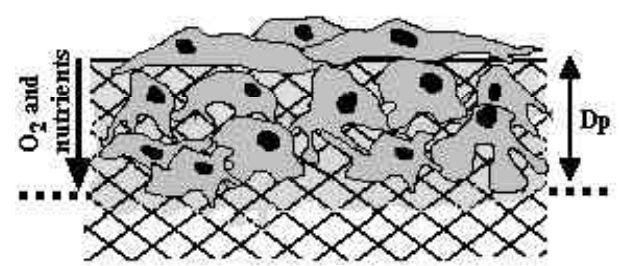

e) The top layer of cells consumes most the oxygen and nutrients in addition to limiting the diffusion of these components, thus reducing the amount available for pioneering cells migrating deep into the scaffold. Eventually, cellular migration is halted due to the lack of oxygen and nutrients supply. The layer of cells that can survive on the diffusion of oxygen and nutrients from the medium is called the cellular penetration depth (Dp).

Figure 1: A schematic diagram showing the diffusion constraints of tissue engineering scaffolds which are foam structures. ever, this approach has resulted in the in vitro growth of tissues with cross-sections of less than $500 \mu \mathrm{m}$ from the external surface (Ishaug-Riley et al., 1997; Freed and Vunjak-Novakovic, 1998). This is probably due to the diffusion constraints of the foam as shown in Figure 1. The pioneering cells cannot migrate deep into the scaffold because of the lack of nutrients and oxygen and insufficient removal of waste products; cell colonisation at the scaffold periphery is consuming, or acting as an effective barrier to the diffusion of, oxygen and nutrients into the interior of the scaffold. Furthermore, for bone tissue engineering, the high rates of nutrient and oxygen transfer at the surface of the scaffold promote the mineralization of the scaffold surface, further limiting the mass transfer to the interior of the scaffold (Martin et al., 1998). Thus cells are only able to survive close to the surface. In this connection, it should be noted that no cell, except for chondrocytes, exists further than $25-100 \mu \mathrm{m}$ away from a blood supply (Vander et al., 1985; Guyton and Hall, 1996). The low oxygen requirement of cartilage may be the reason why only this tissue has been successfully grown in vitro to thick cross-sections i.e. greater than $1 \mathrm{~mm}$ using conventional scaffold fabrication techniques (Freed and Vunjak-Novakovic, 1998). Skin is a relatively 2D tissue and thus thick cross-sections of tissue are not required, thereby explaining the success of producing this tissue with conventional scaffold fabrication techniques (Eaglstein and Falanga, 1997). However, most other 3D tissues require a high oxygen and nutrient concentration.

The human body supplies its tissues with adequate concentrations of oxygen and nutrients via blood vessels. Tissue engineering scaffolds should embrace this approach and have some form of an artificial vascular system present within them to increase the mass transport of oxygen and nutrients deep within, and removal of waste products from, the scaffold. It is in this application that solid freeform fabrication can optimise tissue-engineering scaffolds.

\section{Solid Freeform Fabrication}

The technology transfer of solid freeform fabrication (SFF) to tissue engineering may be the key to produce scaffolds with customised external shape and predefined and reproducible internal morphology, which not only can control pore size, porosity an pore distribution, but can also make structures to increase the mass transport of oxygen and nutrients throughout the scaffold.

SFF technologies involve building 3D objects using layered manufacturing strategies. Although there are several commercial variants of SFF technology, the general process involves producing a computer-generated model using computer-aided design (CAD) software. This CAD model is then expressed as a series of cross-sectional layers. The data is then implemented to the SFF machine, which produces the physical model. Starting from the bottom and building layers up, each newly formed layer adheres to the previous. Each layer corresponds to a crosssectional division. Post-processing may be required to remove temporary support structures.

Furthermore, data obtained from Computerised Tomog- 
raphy (CT) or Magnetic Resonance Imaging (MRI) medical scans can be used to create a customised CAD model and consequently a scaffold possessing the exact external shape required to correct the damaged tissue site. Only the SFF technologies that have been applied to fabrication of tissue engineering scaffolds will be presented below. The reader is referred to Pham and Dimov (2000) for a general review on SFF.

\section{Three Dimensional Printing (3DP)}

(Bredt et al., 1998)

3DP incorporates conventional ink jet printing technology ( $\mathrm{x}$ - and $\mathrm{y}$-axis control) to eject a binder from a jet head, which moves in accordance to the CAD cross-sectional data, onto a polymer powder surface. The binder dissolves and joins adjacent powder particles. The piston chamber is lowered (z-axis control) and refilled with another layer of powder and the process repeated. The unbound powder acts to support overhanging or unconnected features and needs to be removed after component completion. Figure 2 shows this system.

\section{Stereolithography (SLA)}

(Hull, 1990)

The process involves selective polymerisation of a liquid photocurable monomer by an ultraviolet laser beam. The $\mathrm{UV}$ beam is guided ( $\mathrm{x}$ - and $\mathrm{y}$-axis control) onto the liquid monomer surface in accordance to the CAD cross-sectional data. After the first layer is built, the elevator holding the model is lowered into the vat (z-axis control) so as to allow the liquid photopolymer to cover the surface. A 'wiper arm' is then displaced over the liquid to flatten the surface. The procedure is repeated until the model is completed. This system requires support structures to be added to the model, to prevent any overhanging or unconnected features from falling to the bottom of the liquid-filled vat. After completion, the model is raised and any support structures are removed manually. Figure 3 shows this system.

\section{Fused Deposition Modelling (FDM)}

(Scott, 1991)

FDM uses a moving nozzle to extrude a fibre of polymeric material ( $\mathrm{x}$ - and $\mathrm{y}$-axis control) from which the physical model is built layer-by-layer. The model is lowered (z-axis control) and the procedure repeated. Although the fibre must also produce external structures to support overhanging or unconnected features that need to be manually removed, the pore sizes in tissue engineering scaffolds are sufficiently small enough for the fibre strand to bridge across without additional support structures. Figure 4 shows this system.

\section{D Plotter}

\section{(Landers and Mulhaupt, 2000)}

This system, developed by researchers at the University of Freiburg, involves a moving extruder head ( $\mathrm{x}-\mathrm{y}, \mathrm{y}$ - and $\mathrm{z}$-axis control) and uses compressed air to force out a liquid or pastelike plotting medium. The extruder head can be heated to the required temperature. The medium solidifies when it comes in contact with the substrate or previous layer. Figure 5 shows this system.

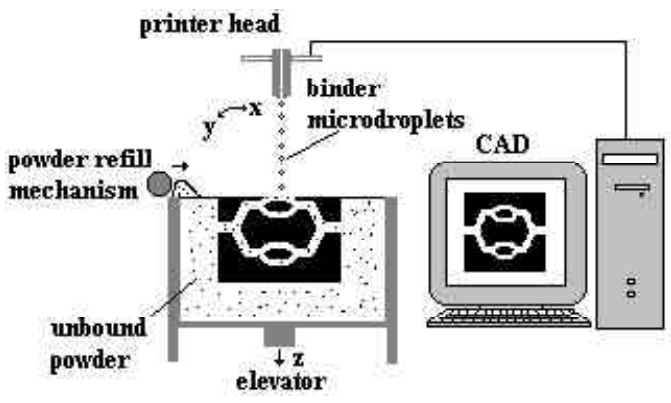

Figure 2: Schematic diagram of the 3D printing (3DP) system.

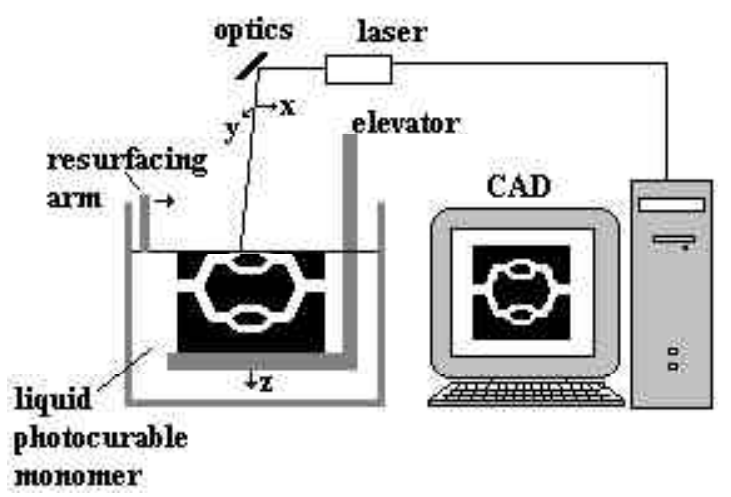

Figure 3: Schematic diagram of the Stereolithography (SLA) system.

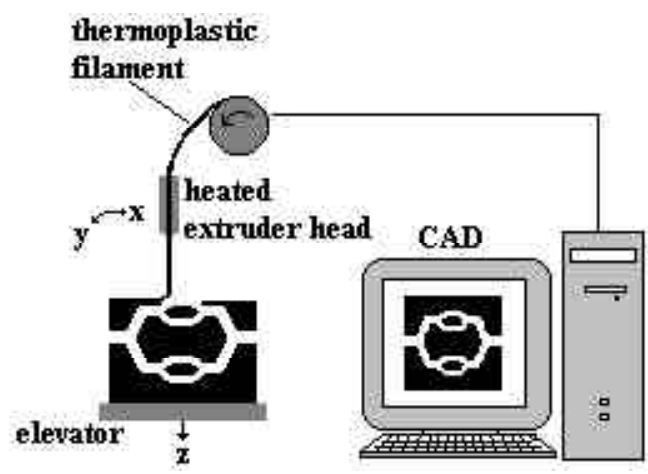

Figure 4: Schematic diagram of the Fused Deposition Modelling (FDM) system.

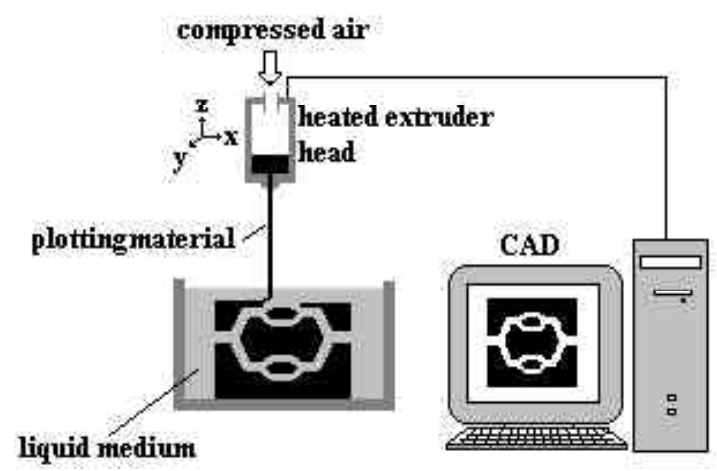

Figure 5: Schematic diagram of the 3D Bioplotter system. 


\section{Phase-change Jet Printing}

(Philbrook et al., 1996)

This system comprises two ink-jet print heads; each delivering a different material, one material for building the actual model and the other acting as support for any unconnected or overhanging features. Molten microdroplets are generated by the jet heads, which are heated above the melting temperature of the material, and deposited in a drop-on-demand fashion. The microdroplets solidify on impact to form a bead. Overlapping of adjacent beads forms a line and overlapping of adjacent lines forms a layer. After layer formation, a horizontal rotary cutter arm can be used to flatten the top surface and control the layer thickness. The platform is lowered and the process is repeated to build the next layer, which adheres to the previous, until the shape of the model is complete. Once built, the model can then be immersed in a selective solvent for the support material, but a nonsolvent for the build material, so as to leave the physical model in its desired shape. Figure 6 shows this system.

\section{Solid Freeform Fabrication in Tissue Engineering}

It is appreciated that computer control of complex internal features of scaffolds, such as pore size, porosity, pore distribution and an artificial vascular system, offered by SFF technologies is a great advantage to the tissue engineer. An artificial vascular system is defined herein as any structures contained within the scaffold that supply and maintain an adequate mass transport of oxygen and nutrients to the cells, and removal of waste metabolites from the cells, throughout the whole scaffold.

The pioneering work of Griffith and co-workers at Massachusetts Institute of Technology resulted in the realisation of tissue engineering scaffolds manufactured with SFF technology (Giordano et al., 1996; Griffith et al., 1997; Park et al., 1998). Scaffolds have been made from PLLA and PLGA by printing chloroform onto a bed of these particles. The chloroform acts to swell, partially dissolve the polymer and eventually bind adjacent particles once the solvent has evaporated. Scaffolds of PLGA were manufactured using 3DP and used for liver tissue engineering (Kim et al., 1998). 3DP was used to create an intricate network of channels running longitudinally and radially through the length of the scaffold. The diameter of these channels was reported to be $800 \mu \mathrm{m}$. The PLGA powder also contained sodium chloride particles, which were removed by leaching with distilled water to create micropores within the scaffold. The drawbacks of 3DP are due to the fact that it is a powder-based process making it difficult to remove support powder from complex channel features deep within the scaffold. Furthermore, organic solvents are used as the binder. After 1 week drying, there still remained $0.5 \%$ wt (5000ppm) chloroform on samples made by 3DP (Giordano et al., 1996). The amount of residual chloroform permitted in drugs, defined by the US Pharmacopoeia, is 60ppm (Federal Register, 1997). Recently, residual chloroform extraction using liquid carbon dioxide has been investigated

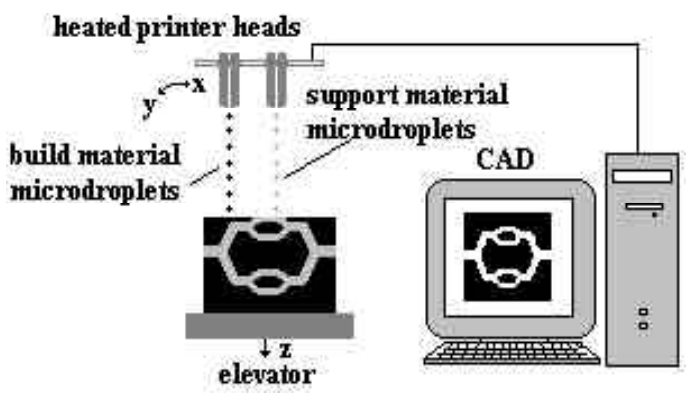

Figure 6: Schematic diagram of the phase change jet printing system, the Model-Maker II (MMII).

(Koegler et al., 2002). This technique reduced the level of chloroform below 50ppm. Lam et al. (2002) used water as a binder with 3DP to produced starch-based polymer scaffolds. However, infiltration of the porous scaffolds with a solution of PLLA and PCL in methylene chloride was required to increase the mechanical strength.

Griffith and Halloran (1996) have reported the fabrication of ceramic parts by SLA. Suspensions of alumina, silicon nitride and silica particles loaded in UVphotocurable monomer were made using SLA. Curing of the monomer resulted in binding of ceramic particles to from a green body. The binder was removed by pyrolysis and the ceramic parts sintered. A suspension of hydroxyapatite (HA) in photocurable monomer was formulated to produce HA scaffolds for orbital floor prosthesis by this same technique (Levy et al., 1997). These HA scaffolds offer superior cosmetic appearance for bone graft applications compared to conventional techniques. Similarly, Porter et al. (2001) formulated suspensions of calcium polyphosphate (CPP) and a photocurable monomer for application to SLA. They reported 25 vol\% CPP suspension, which resulted in amorphous CCP by sintering at $585^{\circ} \mathrm{C}$ compared to crystalline CCP formed at $600^{\circ} \mathrm{C}$. These ceramic scaffolds are limited to bone engineering. Matsuda and Mizutani (2002) have developed a biodegradable, photocurable copolymer, acrylate-endcapped poly(e-caprolactone-co-trimethylene carbonate), which can be used with the SLA apparatus.

FDM has also been adapted for tissue engineering scaffold production. Hutmacher et al. (2001) optimised the processing parameters for the extrusion of PCL filaments to produce honeycomb-like scaffolds. The porosity can be varied between $48-77 \%$, depending on the diameter of the extruder tip (Zein et al., 2002). The channel size ranged between $160 \mathrm{~mm}$ (vertically) and $700 \mu \mathrm{m}$ (horizontally). Cell culturing of these PCL scaffolds showed that human fibroblasts colonized the struts and bars and formed a cell-to-cell and cell-to-extracellular matrix interconnective network throughout the entire 3D honeycomb-like architecture. FDM is an extremely attractive technology for tissue engineering scaffolds in that it does not use toxic organic solvents. However, because the FDM operates at high temperatures $\left(120^{\circ} \mathrm{C}\right)$, this eliminates the incorporation of biological molecules into the process. Woodfield et al. (2002) has made poly(ethylene glycol 
terephthalate)/ poly(butylenes terephthalate) scaffolds using FDM. It is appreciated that there is a narrow processing parameters window for the application of biodegradable polymers with FDM (Landers et al., 2002b).

A much more versatile system that is capable of extruding hotmelts, solutions, pastes and dispersions of polymers as well as monomers and reactive oligomers is the 3D Plotter (Landers and Mulhaupt, 2000). Scaffolds have been made from PLA, PLGA and PCL using this system (Landers et al., 2002a). However, probably the most attractive feature of the 3D Plotter is in the production of hydrogel scaffolds. Landers et al. (2002b) have reported making agar hydrogel scaffolds. The delicate hydrogel strands were supported by dispensing the agar in a liquid medium with matched density and polarity. The agar solution was heated to $70^{\circ} \mathrm{C}$ and then dispensed into an aqueous gelatin solution kept at $20^{\circ} \mathrm{C}$. Gelation of the agar occurs to form a stable gel with some mechanical integrity. Cellular attachment of fibroblasts and osteosarcoma cells on the agar scaffolds was improved by forming a coating based on the reaction of calcium ions with hyaluronic acid and alginic acid. Further treatments to increase the surface roughness of the scaffolds and increase cellular attachment were made. Gelatin hydrogel scaffolds proved difficult to produce because the gel isn't stable at $37^{\circ} \mathrm{C}$. The same investigators have also made fibrin hydrogel scaffolds using reactive plotting (Landers et al., 2002b). The 3D Plotter dispensed a solution of alginic acid and fibrinogen into an aqueous solution containing thrombin and calcium ions. Thrombin is the enzyme which catalyses the polymerisation of fibrinogen to fibrin. Fibrin is formed in the human body by this same process during blood clot formation. Since reactive plotting can be performed at $37^{\circ} \mathrm{C}$, this offers the possibility of incorporating cells into the dispersing solution and create hydrogels with different cell types throughout the scaffold (Landers et al., 2002b).

Ang et al. (2002) describe a rapid prototyping robotic dispensing (RPBOD) system that works on the same principles as the 3D Bioplotter. These investigators reported producing 3D chitosan and chitosan-HA scaffolds using the RPBOD. Solutions of chitosan or chitosan-HA were extruded into a sodium hydroxide and ethanol medium to induce precipitation of chitosan. The concentration of sodium hydroxide was identified as important in controlling the adhesion between layers. The scaffolds were then hydrated, frozen and freeze-dried. Prior to cell culturing with osteogenic cells, the scaffolds were seeded with fibrin glue.

\section{Scaffolds made using solid freeform fabrication moulds}

The above-mentioned techniques aim to produce scaffolds directly from SFF systems. However, a different school of thought involves using the SFF system to make a mould, casting a biocompatible and biodegradable material into the mould and then removing the mould as shown in Figure 7. The mould is designed to possess the negative shape of the envisioned scaffold. The concept for using a mould to make tissue-engineering scaffolds is not new;

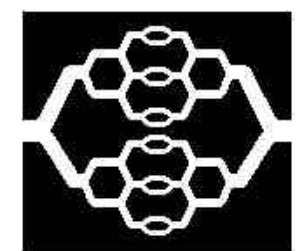

a) Envisioned scaffold

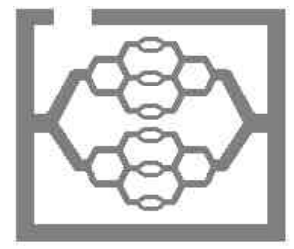

b) Mould, possessing the negative shape of the envisioned scaffold, is designed on a computer workstation using CAD. The mould is manufactured using SFF technology.

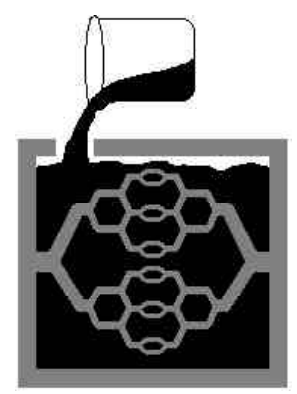

c) Biodegradable material is cast into the mould and solidified.

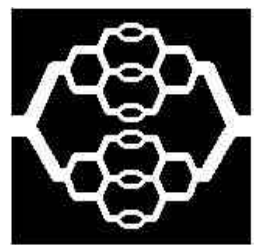

d) Mould is removed by thermal or chemical dissolution techniques to free the scaffold.

Figure 7: The principle of using a sacrificial mould manufactured by SFF to make tissue engineering scaffolds.

Cao et al. (1997) used alginate impression material to make a mould of a 3 year old child's ear. The alginate impression was used to fashion a plaster mould to which a PGA mesh was added and moulded into the shape of the human ear. Jockenhoevle et al., (2001) have made aluminium moulds, resembling the shape of a human aortic valve. A cell suspension of myofibroblasts and fibrinogen was cast into the mould and polymerisation of fibrin was induced.

However, these moulding techniques have only been used to control the external shape of the scaffold; they are unable to make undercut structures inside the scaffold. Chu et al. (2002) has pioneered the application of moulds 
made by SFF to control the internal architecture of the scaffold. Moulds were fabricated with a SLA system using a commercial epoxy resin. A $40 \mathrm{vol} \% \mathrm{HA}$ suspension was cast into the mould and the acrylic-based binder thermally cured. The epoxy mould and acrylic binders were removed by pyrolysis and the remaining HA sintered. Several mould designs were produced, all of which possessed a series of interconnecting shafts of controlled dimensions which dictate the channel structure to be formed in the HA scaffold. The size of channels in the HA scaffold was reported to be $469 \pm 20 \mu \mathrm{m}$ in height and $334 \pm 10 \mu \mathrm{m}$ in width. The reported average compressive strength of $30 \pm 8 \mathrm{MPa}$ of the HA scaffolds is comparable to that of coralline HA (Shors and Holmes, 1993). Implantation of cylindrical shaped scaffolds, with orthogonal and radial channel designs, in the mandible of Yucatan minipigs for 9 weeks revealed a bone penetration depth of $0.7-1.4 \mathrm{~mm}$ in the end sections of both designs, and $1.08+/-4.9 \mathrm{~mm}$ and $1.28+/-0.6 \mathrm{~mm}$ in the middle sections of the orthogonal and radial designs, respectively. Similarly, Bose et al. (2002) fabricated alumina scaffolds with moulds made by FDM using commercially available ICW06 thermoplastic wax. The alumina scaffolds were coated with HA to make the scaffolds bioactive. These bioceramic scaffolds are limited to bone tissue engineering and the high binder burn out temperatures $\left(550^{\circ} \mathrm{C}\right)$ eliminates the possibility of making biodegradable polymer scaffolds with this process.

Taboas et al. (2003) have cast a solution of PLLA and chloroform into wax and ceramic moulds to create channelled structures. Salt particles were added to the mould, and removed by leaching, to create interconnected pores within the polymer matrix. PLLA/PGA composites were also made by a two-step melt casting procedure using a ceramic mould. HA/PLLA composites were produced using a similar process. The ceramic moulds were removed by chemical dissolution using RDO (a commercial decalcifier). This process uses organic solvents for casting and mould removal, thus raising the issue of whether toxic residues are present on the scaffold.

A process developed at the University of Oxford and UMIST has resulted in the production of collagen scaffolds with controlled and predefined internal morphology (Sachlos et al., 2003). The process begins with a mould, which is manufactured using a phase-change inkjet printer, the Model-Maker II. The mould possesses a series of interconnected and branched shafts running across the walls of the mould. A dispersion of collagen type $\mathrm{I}$ is cast into the mould and frozen at $-20^{\circ} \mathrm{C}$. The mould containing the frozen collagen is then immersed in ethanol, which dissolves the mould and ice crystals to leave a porous collagen structure containing channels that are predefined by the mould. The channel width and height size can be adjusted to a minimum of $200 \pm 20 \mu \mathrm{m}$. Ethanol is probably a more appropriate organic solvent to tissue engineering scaffold processing because any residues should not be significantly deleterious to cells. The ethanol is then removed by critical point drying with liquid carbon dioxide. The result is a dry collagen scaffold, shown in Figure 8, which is ready for subsequent crosslinking, rehydration and cell culturing. The process

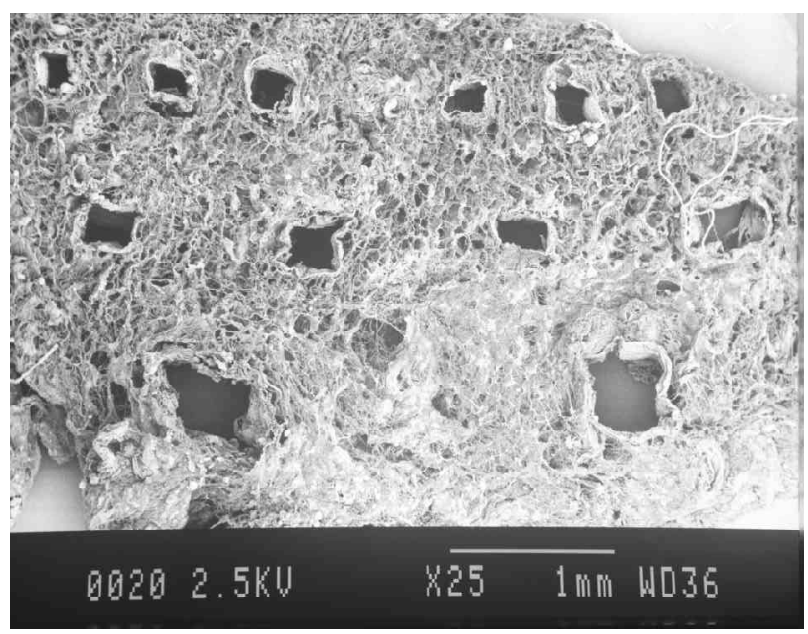

Figure 8: SEM image showing cross-section through a collagen scaffold made with SFF mould. Note the well-defined square channels and the size of these channels which range from $170-450 \mu \mathrm{m}$.

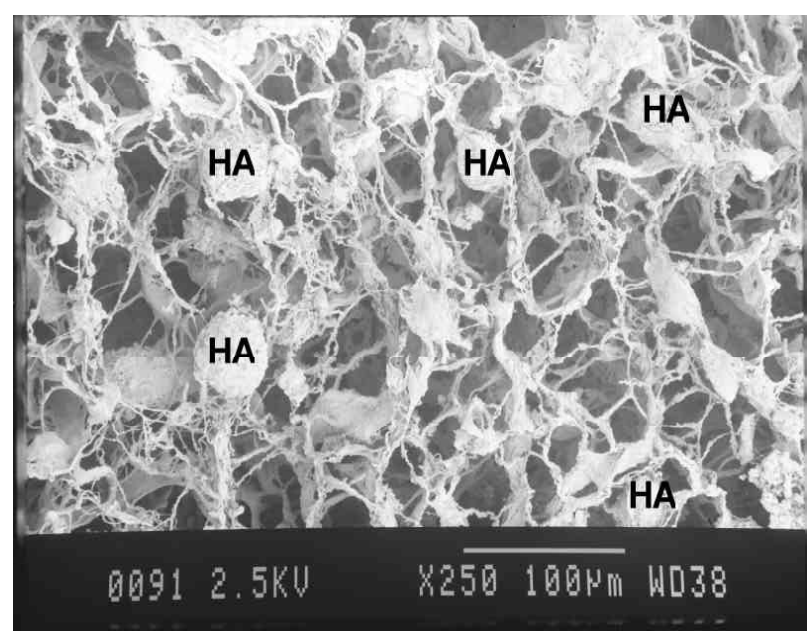

Figure 9: SEM image showing a composite scaffold with hydroxyapatite particles embedded throughout the collagen matrix. Note the open-cell porosity of the collagen matrix.

is attractive in that collagen is used as the scaffold material. The processing temperature never exceeds $36^{\circ} \mathrm{C}$, therefore preventing the denaturing of the collagen molecules and offers the possibility of incorporating other biological molecules, e.g. growth factors. These collagen scaffolds are intended for the engineering of soft tissues. Composite scaffolds have also been formed by adding $70 \%$ weight HA particles into the collagen dispersion and then processing as shown in Figure 9. These composite scaffolds provide a chemical environment characteristic of bone and are intended for engineering of this tissue. The moulds are made from the commercial thermoplastic materials, ProtoBuild ${ }^{\mathrm{TM}}$. Research efforts are aimed at making for scaffolds of type I collagen for use in hard and soft tissue augmentation using non-toxic solvents and materials. 


\section{Conclusion}

In summary, tissue-engineering scaffolds made from conventional fabrication techniques are inadequate for the growth of thick cross-sections of tissue due to the diffusion constraints posed by foam structures. Solid freeform fabrication systems provide a solution to this problem by creating scaffolds with controlled internal microarchitecture, which should increase the mass transport of oxygen and nutrients deep into the scaffold. Several systems have been successfully adapted to produce synthetic and natural biodegradable polymer, bioceramic and hydrogel scaffolds. However, shortcomings arise from difficulty in support powder removal, use of toxic organic binders, high temperature processing preventing the use of biological molecules and poor mechanical strength. The use of sacrificial moulds made by SFF systems avoids some of these processing issues whilst retaining the computer control and high resolution offered by SFF. Optimising the scaffold is essential if tissue engineering is going to be successful in replacing or repairing damaged human tissues. SFF has the potential to optimise these scaffolds and make them work.

\section{References}

Agrawal CM, Ray RB (2001) Biodegradable polymeric scaffolds for musculoskeletal tissue engineering. J Biomed Mater Res 55: 141-150.

Alberts B, Bray D, Lewis J, Raff M, Roberts K, Watson JD (1994). Molecular Biology of the Cell, $3^{\text {rd }}$ edition. Garland Publishing Ltd, New York. pp 971-1000.

Ang TH, Sultana FSA, Hutmacher DW, Wong YS, Fuh JYH, Mo XM, Loh HT, Burdet E, Teoh SH (2002) Fabrication of 3D chitosan-hydroxyapatite scaffolds using a robotic dispensing system. Mater Sci Eng C20: 35 42.

Arem A (1985) Collagen modifications. Clin Plast Surg 12: 209-220.

Bose S, Darsell J, Hosick H, Yany L, Sarrkar DK, Bandyopahhyay A (2002): Processing and characterization of porous alumina scaffolds. J Mater Sci: Mat M 13: 23-28.

Bredt JF, Sach E, Brancazio D, Cima M, Curodeau A, Fan T (1998) Three dimensional printing system. US Patent 5807437.

Bergsma JE, de Bruijn WC, Rozema FR, Bos RR, Boering G (1995) Late degradation tissue response to poly(L-lactide) bone plates and screws. Biomaterials 16: 25-31.

Burg KJL, Porter S, Kellam JF (2000) Biomaterial developments for bone tissue engineering. Biomaterials 21: 2347-2359.

Cao Y, Vacanti JP, Paige KT, Upton J, Vacanti CA (1997) Transplantation of chondrocytes utilizing a polymer-cell construct to produce tissue-engineered cartilage in the shape of a human ear. Plast Reconstr Surg 100: 297-302.

Chevally B, Herbage D (2000) Collagen-based biomaterials as 3D scaffold for cell cultures: applications for tissue engineering and gene therapy. Med Biol Eng Comput 38: 211-218.

Chu TMG, Orton DG, Hollister SJ, Feinberg SE, Halloran JW (2002) Mechanical and in vivo performance of hydroxyapatite implants with controlled architectures. Biomaterials 23: 1283-1293.

Cima LG, Vacanti JP, Vacanti C, Inger D, Mooney D, Langer R (1991). Tissue engineering by cell transplantation using degradable polymer substrates. J Biomech EngT ASME 113: 143-151.

Dagalakis N, Flink J, Stasikelis P, Burke JF, Yannas IV (1980) Design of an artificial skin. Part III. Control of pore structure. Biomaterials 14: 511-528.

Doillon CJ, Whyne CF, Brandwein S, Silver FH. (1986) Collagen-based wound dressings: Control of the pore structure and morphology. J Biomed Mater Res 20: 1219-1228.

Eaglstein WH, Falanga V (1997): Tissue engineering and the development of Apligraf ${ }^{\circledR}$, a human skin equivalent, Clin Ther 19: 894-905.

Federal Register (1997). Q3C Impurities: Residual Solvents. US Department of Health and Human Services: Food and Drug Administration. Federal Register 62, pp. 67377-67388.

Freed LE, Vunjak-Novakovic G (1998) Culture of organized cell communities. Adv Drug Deliver Rev 33: 1530 .

Giordano RA, Wu BM, Borland SW, Cima LG, Sachs EM, Cima MJ (1996) Mechanical properties of dense polylactic acid structures fabricated by three dimensional printing. J Biomat Sci-Polym E 8: 63-75.

Glicklis R, Shapiro L, Agbaria R, Merchuk JC, Cohen S (2000) Hepatocyte behavior within three-dimensional porous alginate scaffolds. Biotechnol Bioeng 67: 344-353.

Griffith ML, Halloran JW (1996) Freeform fabrication of ceramics via stereolithography. J Am Ceram Soc 79: 2601-2608.

Griffith LG (2000). Polymeric biomaterials. Acta Mater 48: 263-277.

Griffith LG, Wu BM, Cima MJ, Powers MJ, Chaignaud B, Vacanti JP (1997) In vitro organogenesis of liver tissue. Ann N Y Acad Sci 831: 382-397.

Guyton AC, Hall JE (1996) Textbook of Medical Physiology, $6^{\text {th }}$ edition. WB Saunders, Philadelphia. pp. 183197.

Hayashi T (1994) Biodegradable polymers for biomedical uses. Prog Polym Sci 19: 663-702.

Hsu YY, Gresser JD, Trantolo DJ, Lyons CM, Gangadharam PRJ, Wise DL (1997) Effect of polymer foam morphology and density on kinetics of in vitro controlled release of isoniazid from compressed foam matrices. J Biomed Mater Sci 35: 107-116.

Hull C (1990) Method for production of three-dimensional objects by stereolithography. US Patent 4929402

Hutmacher DW (2001) Scaffold design and fabrication technologies for engineering tissues-state of the art and future perspectives. J Biomat Sci-Polym E 12: 107124.

Hutmacher DW, Schantz T, Zein I, Ng KW, Teoh SH, Tan KC (2001) Mechanical properties and cell cultural 
response of polycaprolactone scaffolds designed and fabricated via fused deposition modeling. J Biomed Mater Res 55: 203-216.

Ishaug-Riley SL, Crane GM, Gurlek A, Miller MJ, Yasko AW, Yaszemski MJ, Mikos AG (1997): Ectopic bone formation by marrow stromal osteoblast transplantation using poly(DL-lactic-co-glycolic acid) foams implanted into the rat mesentery. J Biomed Mater Res 36: 18.

Jockenhoevle S, Zund G, Hoerstrup SP, Chalabi K, Sachweh JS, Demircan L, Messmer BJ, Turina M (2001) Fibrin gel-advantages of a new scaffold in cardiovascular tissue engineering. Eur J Cardio-Thorac 13: 424-430.

Kim SS, Utsunomiya H, Koski JA, Wu BM, Cima MJ, Sohn J, Mukai M, Griffith LG, Vacanti JP (1998) Survival and function of hepatocytes on a novel three-dimensional synthetic biodegradable polymer scaffold with an intrinsic network of channels. Ann Surg 228: 8-13

Kleinman HK, Klebe RJ, Martin GR (1981). Role of collagenous matrices in the adhesion and growth of cells. J Cell Biol 88: 473-485.

Koegler WS, Patrick C, Cima MJ, Griffith LG (2002) Carbon dioxide extraction of residual chloroform from biodegradable polymers. J Biomed Mater Res 63: $567-$ 576.

Kohn DG, Sarmadi M, Helman JI, Krebsbach PH (2002) Effects of $\mathrm{pH}$ on human bone marrow stromal cells in vitro: Implications for tissue engineering of bone. $\mathrm{J}$ Biomed Mater Res 60: 292-299.

Lam EXF, Mo XM, Teoh SH, Hutmacher DW (2002) Scaffold development using 3D printing with a starchbased polymer. Mat Sci Eng C20: 49-56.

Landers R, Mulhaupt R (2000) Desktop manufacturing of complex objects, prototypes and biomedical scaffolds by means of computer-assisted design combined with computer-guided 3D plotting of polymers and reactive oligomers. Macromol Mater Eng 282: 17-21.

Landers R, Hubner U, Schmelzeisen R, Mulhaupt R (2002a). 3D Plotting. Proceedings of Rapid Prototyping for Biomedical Applications: from Implants to Organ Printing Workshop, Freiburg, Germany, 31 May 2002. Workshop organised by Landers R, Pfister A, Mulhaupt R, Freiburger Materialforschungszentrum and Institut fur Makromolekulare Chemie of the Albert Ludwigs University Freiburg, Germany.

Landers R, Pfister A, Hubner U, John H, Schmelzeisen R, Mulhaupt R (2002b) Fabrication of soft tissue engineering scaffolds by means of rapid prototyping techniques. J Mater Sci 37: 3107-3116.

Langer R, Vacanti JP (1993) Tissue engineering. Science 260: 920-926.

LeGeros RZ (2002) Properties of osteoconductive biomaterials: calcium phosphates. Clin Orthop Relat Res 395: 81-98.

Levy RA, Chu TGM, Halloran JW, Feinberg SE, Hollister S (1997) CT-generated porous hydroxyapatite orbital floor prosthesis as a prototype bioimplant. Am J Neuroradiol 18: 1522-1525.

Lo H, Ponticiello MS, Leong KW (1995): Fabrication of controlled release biodegradable foams by phase separation. Tissue Eng 1: 15-28.
Madihally SV, Matthew HWT (1999) Porous chitosan scaffolds for tissue engineering. Biomaterials 20: 11331142 .

Martin I, Padera RF, Vunjak-Novakovic G, Freed LE (1998) In vitro differentiation of chick embryo bone marrow stromal cells into cartilaginous and bone-like tissues. J Orthopaed Res 16: 181-189.

Matsuda T, Mizutani M (2002) Liquid acrylateendcapped biodegradable poly(e-caprolactone- $c o$-trimethylene carbonate). II. Computer-aided stereolithographic microarchitectural surface photoconstructs. J Biomed Mater Res 62: 395-403.

Mikos AG, Sarakinos G, Leite SM, Vacanti JP, Langer R (1993a): Laminated three-dimensional biodegradable foams for use in tissue engineering. Biomaterials 14: 323330.

Mikos AG, Bao Y, Cima LG, Ingber DE, Vacanti JP, Langer R (1993b): Preparation of poly (glycolic acid) bonded fibres structures for cell attachment and transplantation. J Biomed Mater Res, 27: 183-189.

Mikos AG, Thorsen AJ, Czerwonka LA, Bao Y, Langer R (1994) Preparation and characterisation of poly(L-lactic acid) foams. Polymer 35: 1068-1077.

Mikos AG, Sarakinos G, Vacanti JP, Langer R, Cima LG (1996) Biocompatible polymer membranes and methods of preparation of three dimensional membrane structures. US Patent Number 5514378

Miyata T, Sohde T, Rubin AL, Stenzel KH (1971) Effects of ultraviolet irradiation on native and telopeptidepoor collagen. Biochim Biophy Acta 229: 672-680.

Miyata T, Rubin AL, Dunn MW, Stenzel KH (1980) Collagen soft contact lens. US Patent 4223984

Mooney DJ, Baldwin DF, Suh NP, Vacanti JP, Langer R (1996) Novel approach to fabricate porous sponges of poly(D,L-lactic co-glycolic acid) without the use of organic solvents. Biomaterials 17: 1417-1422.

Olde Damink LHH, Dijkstra PJ, Van Luyn MJA, Van Wachem PB, Nieuwenhuis P, Feijen J (1995) Crosslinking of dermal sheep collagen using hexamethylene diisocyanate. J Mat Sci: Mater Med 6: 429-434

Park A, Wu B, Griffith LG (1998) Integration of surface modification and $3 \mathrm{D}$ fabrication techniques to prepare patterned poly(L-lactide) substrates allowing regionally selective cell adhesion. J Biomater Sci-Polym E 9: 89-110.

Patrick CW, Mikos AG, McIntire LV (1998) Prospects of tissue engineering. In: Frontiers in Tissue Engineering. Patrick CW, Mikos AG, McIntire LV, eds. Elsevier Science Ltd, Oxford. pp. 3-11.

Pham DT, Dimov SS (2000) Rapid prototyping processes. In: Rapid Manufacturing: the Technologies and Applications of Rapid Prototyping and Rapid Tooling. Pham DT, Dimov SS, eds. Springer, London. pp.19-42.

Philbrook KF, Sanders JR, Royden C, Forsyth JL (1996) 3-D model maker. US Patent 5506607.

Porter NL, Pilliar RM, Grynpas MD (2001) Fabrication of porous calcium polyphosphate implants by solid freeform fabrication: A study of processing and in vitro degradation characteristics. J Biomed Mat Res 56: 504515.

Postlethwaite AE, Seyer JM, Kang AH (1978). 
Chemotactic attraction of human fibroblasts by type I, II and III collagens and collagen-derived peptides. Proc Natl Acad Sci USA 75: 871-875.

Reed AM, Gilding DK (1981) Biodegradable polymer for use in surgery - poly(glycolic)/poly(lactic acid) homo and copolymers: 2 . In vitro degradation. Polymer, 22: 342-346.

Reuber M, Yu LS, Kolff WJ (1987) Effect of processing temperature on the properties of polyurethane and comparison of vacuum forming and solution casting to make artificial hearts. Artif Organs 11: 323-323.

Ruijgrok JM, De Wijhn JR, Boon ME (1994) Optimizing glutaraldehyde crosslinking of collagen: effect of time, temperature and concentration as measured by shrinkage temperature. J Mater Sci: Mater Med 5: 8087.

Sachlos E, Reis N, Ainsley C, Derby B, Czernuszka JT (2003) Novel collagen scaffolds with predefined internal morphology made by solid freeform fabrication. Biomaterials 24: 1487-1497.

Schmitz JP, Hollinger JO (1988) A preliminary study of the osteogenic potential of a biodegradable alloplasticosteoinductive alloimplant. Clin Orthop 237, 245-255

Schoof H, Apel J, Heschel I, Rau G (2001) Control of pore structure and size in freeze-dried collagen sponges. J Biomed Mater Res-A 58: 352-357.

Schoof H, Burns L, Fisher A, Heschel I, Rau G (2000) Dendritic ice morphology in unidirectionally solidified collagen suspensions. J Cryst Growth 209: 122-129.

Scott CS (1991) Apparatus and method for creating three-dimensional objects. US Patent 5121329.

Shalak R, Fox CF (1988). Preface. In: Tissue Engineering. Shalak R, Fox CF, eds. Alan R.Liss, New York. pp. 26-29.

Shors E, Holmes R (1993) Porous hydroxyapatite. In: An Introduction to Bioceramics. Hench L, Wilson J, eds. World Scientific, Singapore. pp 181-198.

Suganuma J, Alexander H (1993) Biological response of intramedullary bone to poly-L-lactic acid. J Appl Biomater 4: 13-27.

Taboas JM, Maddox RD, Krebsbach PH, Hollister SJ (2003) Indirect solid free form fabrication of local and global porous, biomimetic and composite 3D polymerceramic scaffolds. Biomaterials 24: 181-194.

Thompson JI, Czernuszka JT (1995) The effect of two types of crosslinking on some mechanical properties of collagen. Biomed Mater Eng 5: 37-48.

Thompson RC, Yaszemski MJ, Powers JM, Mikos AG (1995a) Fabrication of biodegradable polymer scaffolds to engineering trabecular bone. J Biomater Sci-Polym E 7: 23-38.

Thompson RC, Yaszembksi MJ, Powers JM, Harrigan TP, Mikos AG (1995b) Poly(a-hydroxy ester)/short fiber hydroxyapatite composite foams for orthopedic applications. In: Polymers in Medicine and Pharmacy, Vol 394. Mikos AG, Leong KW, Yaszemski MJ, eds. Materials Research Society Symposium Proceedings, Pittsburgh. pp. 25-30.

Vander AJ, Sherman JH, Luciano DS (1985). Human Physiology. McGraw-Hill, New York. pp. 341, 366.
Vert M., Mauduit J, Li S (1994) Biodegradation of PLA/GA polymers: increasing complexity. Biomaterials 15: $1209-1213$.

Wake MC, Gerecht PD, Lu LC, Mikos AG (1998) Effects of biodegradable polymer particles on rat marrowderived stromal osteoblasts in vitro. Biomaterials 19, 12551268.

Weadock K, Olson RM, Silver FH (1983-84): Evaluation of collagen crosslinking techniques. Biomater Artif Cell 11: 293-318.

Whang K, Thomas CK, Nuber G, Healy KE (1995) A novel method to fabricate bioabsorbable scaffolds. Polymer 36: 837.

Woodfield T, Malda J, de Wijn J , Riesle J, van Blitterwijk CA (2002) Proceedings of Rapid Prototyping for Biomedical Applications: from Implants to Organ Printing Workshop, Freiburg, Germany, 31 May 2002. Workshop organised by Landers R, Pfister A, Mulhaupt R, Freiburger Materialforschungszentrum and Institut fur Makromolekulare Chemie of the Albert Ludwigs University Freiburg, Germany.

Yannas IV, Burke JF, Gordon PL, Huang C, Rubenstein RH (1980) Design of an artificial skin. Part II. Control of chemical composition. Biomaterials 14: 107-131.

Zein I, Hutmacher DW, Tan KC, Teoh SH (2002) Fused deposition modelling of novel scaffold architectures for tissue engineering applications. Biomaterials 23: 11691185.

\section{Discussion with Reviewers}

S. Gogolewski: The authors state "Conventional scaffold fabrication techniques are incapable of precisely controlling pore size, pore geometry, spatial distribution of pores and construction of internal channels within the scaffold. Scaffolds produced by solvent-casting particulate-leaching cannot guarantee interconnection of pores because this is dependent on whether the adjacent salt particles are in contact. Furthermore, skin layers are formed during evaporation and agglomeration of salt particles makes controlling the pore size difficult (Hutmacher, 2001). Moreover, only thin scaffold cross-sections can be produced due to difficulty in removing salt particles deep in the matrix ". This statement is too general and not justified. Look for example in Gugala and Gogolewski (2000). The polylactide scaffold has interconnected open pores, well-controlled pore size, no skin layers and no salt particles deep in the matrix.

Authors: The use of SFF allows us to control channels and their interconnectivity with a diameter of approximately $200 \mu \mathrm{m}$. The use of a porogen will give rise to a distribution of pore sizes and their interconectivity (which my well be present) cannot be controlled in the same way as by SFF. It is this level of control of the internal (and external) architecture which makes SFF so potentially exciting. Of course, the matrix between the channels can be porous with interconectivity if so desired. We stand by our assertion that current tissue engineering scaffolds without controlled internal channels cannot allow cells to maintain viability deep within the scaffold. 
M. Dalby: For the collagen / HA composite intended for bone tissue engineering, how mechanically similar to bone is the material and what is the percentage of HA incorporated - will there be enough to truly effect osteoblast response? In order for such a material to be used in loadbearing applications, the material should be able to support the rigors of walking etc. Perhaps it is intended that once osseointegration has taken place the formation of bone within the scaffold will be able to take the load?

A. Curtis: Would the authors like to comment on (1) The degree of accuracy and reproducibility in fabrication that is desired, and (2) The desirable mechanical properties of the polymer?

Authors: These two questions are answered together. The mechanical properties of the scaffold can be tailored to suit the particular requirements. Thus, a material with a low elastic modulus would be more suitable as a scaffold for an arterial graft, whereas higher values of the Young Modulus would be required for bone augmentation. The modulus is controlled via several routes - firstly by the components comprising the scaffold itself, secondly the scale and size of the porosity and thirdly, the dimensions and shape of any internal channels. It is this degree of control which makes solid free-form fabrication such a useful tool in making scaffolds. The scaffold of bone tissue augmentation has a Young's modulus of approximately $2 \mathrm{GPa}$.. This is similar to many artificial polymers, but we use the natural components - collagen and hydroxyapatite. The response of osteoprogenitor cells to this class of biomaterial is superior to that found with artificial polymers.

\section{Additional Reference}

Gugala Z, Gogolewski S (2000) In vitro growth and activity of primary chondrocytes on a resorbable polylactide three-dimensional scaffold. J Biomed Mater Res49: 183-191. 